\section{Cerebrovascular \\ Diseases}

Anqi, Q. 23

Borsotto, M. 1

Bousser, M.-G. IV

Chan, B. 18

Chan, E.S.-Y. 8

Chang, H.M. 18

Chen, A. 23

Chen, C. 8, 18, 30

Chen, C.L.H. 23

de Silva, A. 18

Gandin, C. 1

Heurteaux, C. 1
Ikram, K. 23

Lai, M.K.P. 30

Lazdunski, M. 1

Lim, Y.A. 30

Moha ou Maati, H. 1

Murray, L.A. 30

Navarro, J. 18

Onteniente, B. 1

Quintard, H. 1

Siddiqui, F.J. 8
Tan, S.B. 18

Tay, S.S. 18

Umapathi, T. 18

Venketasubramanian, N. 8, 18, 23

Veyssiere, J. 1

Widmann, C. 1

Wong, L. 18

Yin, W.T. 23

Young, S. 18

Zhao, Y.-D. 18

\title{
Subject Index Vol. 35, Suppl. 1, 2013
}

Alzheimer's disease 30

Amyloid precursor protein 30

Barthel Index 8

Brain plasticity 1

Cardiac arrest 1

Cognitive impairment 23

Danqi Piantang Jiaonang 8
Functional independence 8

Meta-analysis 8

MLC601 1, 8, 23, 30

MLC901 1, 23

NeuroAiD 1, 8, 18, 23, 30

Neurogenesis 1, 23

Neuroplasticity 23

Neuroprotection 1, 23
Randomized 8

Recovery 8, 18

Stroke 1, 8, 18, 23, 30

Systematic review 8

Traditional Chinese medicine 18 Trial 8

\section{KARGER}

๑) 2013 S. Karger AG, Basel 